\title{
Translation, Cross-cultural Adaptation and Reliability Analysis of the Survey of Anxiety and Information for Dentists (SAID) among Brazilian Adolescents
}

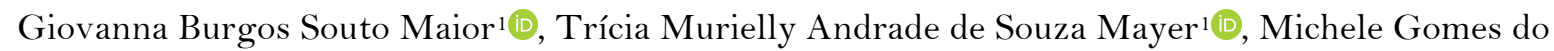 \\ Nascimento ${ }^{1}\left[\right.$, Linda Jones ${ }^{2}\left[\right.$, Viviane Colares ${ }^{1,3}$ (D)
}

${ }^{1}$ Graduate Program in Dentistry, Pernambuco College of Dentistry, University of Pernambuco, Recife, PE, Brazil.

${ }^{2}$ School of Psychology, Massey University, Wellington, New Zealand.

${ }^{3}$ Department of Clinical and Preventive Dentistry, Federal University of Pernambuco, Recife, PE, Brazil.

Correspondence: Viviane Colares, University of Pernambuco, Reitoria/UPE, Agamenon Magalhães Ave, Santo Amaro, Recife, PE, Brazil.50100-010. E-mail: viviane.colares@upe.br

Academic Editor: Alessandro Leite Cavalcanti

Received: 10 February 2021 / Review: 09 April 2021 / Accepted: 28 May 2021

\footnotetext{
How to cite: Maior GBS, Mayer TMAS, Nascimento MG, Jones L, Colares V. Translation, cross-cultural adaptation and reliability analysis of the survey of anxiety and information for dentists (SAID) among Brazilian adolescents. Pesqui Bras Odontopediatria Clín Integr. 2021; 21 e2 10037. https://doi.org/10.1590/pboci.2021.148
}

\begin{abstract}
Objective: To translate, perform a cross-cultural adaptation and reliability analysis of the Survey of Anxiety and Information for Dentists (SAID) for use with Brazilian adolescents. Material and Methods: The SAID was translated into Brazilian Portuguese and back-translated to English. An expert committee compared both versions and examined their equivalence. Then, a face validation was performed with 10 adolescents. The SAID was applied in printed format with 25 questions. Participants answered and commented on the questions with a researcher to confirm the understanding and provide suggestions. The suggestions were implemented, and the expert committee approved the final version of the SAID in Brazilian Portuguese. The psychometric properties were tested with 60 adolescents aged 10 to 19 years. Participants answered the Brazilian version of the SAID before their first dental appointment and two weeks later to determine test-retest reliability. Reliability was analyzed by internal consistency analysis (Cronbach's alpha) and test-retest (ICC). Results: The instrument presented excellent reliability according to internal consistency (Cronbach's alpha $=0.77$ ) and test-retest coefficients $(\mathrm{ICC}=0.88$; $95 \% \mathrm{CI}$ : 0.81 0.93). The Kappa coefficients and the degree of agreement of the dichotomous questions indicated good reproducibility of the new version. Conclusion: The SAID translation, cross-cultural adaptation and reliability analysis were completed successfully. Thus, the Brazilian version of the SAID can be a useful survey tool for dental care of adolescent patients.
\end{abstract}

Keywords: Dentist-Patient Relations; Health Communication; Dental Anxiety; Validation Study. 


\section{Introduction}

Adolescence is a transitional phase from childhood to adulthood that encompasses several physical, cognitive, and psychosocial changes. Adolescents may experience introspection feelings and anxiety, which could potentially compromise their ability to express feelings and communicate with others [1-3]. Thus, one of the major challenges in the dental care of adolescent patients lies in the patient-professional communication and dental anxiety control, since adolescents may not accept children's behavioural techniques anymore nor want to be treated as adults [4,5].

Studies have shown a variable prevalence of dental anxiety among adolescents [6-8]. In Brazil, the prevalence of moderate to severe dental anxiety was approximately 18\% among 12-18-year-old adolescents. Dental anxiety has been associated with lack of economic resources, negligence of oral hygiene, low educational level, female gender, and younger age [9]. Dental anxiety increases the avoidance of health care, and along with the adolescent's introspection and difficulty of establishing personal ties, it may compromise the professional-patient relationship [10].

The Survey of Anxiety and Information for Dentists (SAID) was developed to allow adolescents to report to dentists their feelings and preferences regarding dental care. The SAID aims to improve empathy, which is a key aspect to facilitate communication, treatment compliance, patient satisfaction, and reduction of dental anxiety [10]. This is the first instrument of this category designed for children and adolescents, which was previously validated in New Zealand in paediatric patients aged 10 to 13 years [10,11].

The understanding of adolescents' habits, attitudes, concepts, and preferences may help establishing a relationship of empathy while encouraging regular dental care visits [11]. Thus, considering the difficulty of communication with adolescents and the importance of the professional-patient relationship for cooperation, this study aimed to translate, perform a cross-cultural adaptation and reliability analysis of the SAID for use with Brazilian adolescents.

\section{Material and Methods}

Ethical Statement

This study was previously approved by the Research Ethics Committee at the University of Pernambuco under protocol number 3.080.446. Those willing to participate in the study signed an informed consent form, which was also obtained from minors' parents / legal guardians.

\section{Study Design}

This was a study of translation, cross-cultural adaptation, and validation of the SAID instrument, which was originally developed for the English language. This study was conducted in the city of Recife, Pernambuco, Brazil, at the Adolescent Dental Clinic of the Federal University of Pernambuco (UFPE), with male and female adolescents aged 10 to 19 years. This is the age range corresponding to adolescence, according to the World Health Organization [12,13].

Brazilian adolescents who were visiting the Adolescent Dental Clinic for the first time and were literate in Portuguese, were considered eligible. Those with any cognitive, sensorial, or physical disability (not capable of reading and/or writing) were excluded from the study.

\section{Research Instrument}


The SAID enclosed 25 short and direct questions (see appendix). It was applied in printed format. First question was multiple-choice $(\mathrm{Q} 1)$; four questions had dichotomous answers and we added a blank space for comments or interrogations to dentists (Q22, Q23, Q24, and $\left.\mathrm{Q}^{25}\right)$. The remaining questionnaire consisted of scale-like questions, with up to seven response options. Of these, thirteen could be answered on a face scale, which represented patient's feelings (Q2, Q3, Q4, Q5, Q7, Q8, Q9, Q10, Q13, Q14, Q16, Q17, Q19) and seven questions could be answered as a Likert scale $\left(\mathrm{Q} 6, \mathrm{Q} 11, \mathrm{Q} 12, \mathrm{Q} 15, \mathrm{Q} 18, \mathrm{Q} 20, \mathrm{Q}^{21}\right)$. Closing the questionnaire, question Q4 ("How do you feel about your appointment with the dentist today?") was reprised in order to reevaluate dental anxiety. The SAID assesses four domains, that is: dental neglect, dental anxiety, coping preferences, and patient requests [11].

\section{Procedures}

The first phase of the study consisted of translating the English version of the SAID into Brazilian Portuguese. The instrument was translated by a paediatric dentist fluent in English and whose first language was Brazilian Portuguese. Subsequently, a back-translation was performed by a professional translator whose first language is English but who had extensive knowledge of the Portuguese language. The translator was completely blinded to the original version of the SAID.

In the second phase of the study, the back-translated version was reviewed and compared against the original version by an expert committee composed of three paediatric dentists for cross-cultural adaptation (semantic equivalence). There were minor differences between the versions, but they were only related to synonyms. This version was then sent to the authors of the original instrument for approval. No alterations were suggested.

The third phase of the study consisted of face validation of the Brazilian Portuguese version in a sample of ten adolescents. This procedure was carried out in a reserved room at the Adolescent Dental Clinic of the Federal University of Pernambuco and aimed to determine whether the instructions, items, response options, and vocabulary were well understood by the target population. The adolescents answered the instrument and commented on the questions with a single researcher to confirm the understanding and provide suggestions. These suggestions were implemented by the expert committee, which approved the final version of the questionnaire in Brazilian Portuguese. All previous phases were designed to assure that the Brazilian version of the SAID had conceptual, item, semantic, operational, and functional equivalence [14].

The fourth phase of the study aimed to test psychometric properties and was conducted by two researchers in a non-probabilistic sample of 60 adolescents. They received the Brazilian version of the SAID in printed format, in the adolescent clinic waiting room, before the screening visit. This first visit consisted of a brief evaluation of adolescents' demands. Two weeks after the application of the questionnaire, study participants were asked to answer it once more for test-retest reliability. One of the researchers reapplied the SAID (Brazilian version) to 30 adolescents, while a second researcher reapplied it to the other 30 participants (Figure 1), before their dental care appointment. In this second visit, standardized procedures of anamnesis, dental prophylaxis and physical examination were performed.

\section{Statistical Analysis}

The reliability of the Brazilian version of the SAID was evaluated through the assessment of internal consistency (Cronbach's alpha) and test-retest (Intraclass Correlation Coefficients - ICC). Values $\geq 0.70$ were 
considered acceptable. The ICC was categorised as follows: $\leq$ 0.40, weak correlation; 0.41-0.60, moderate correlation; 0.61-0.80, good correlation; and 0.81-1.00, excellent correlation. Reproducibility (Kappa test) was evaluated based on dichotomous questions [15-18]. All statistical analyses were performed in the Statistical Package for Social Sciences (SPSS for Windows, version 25.0, IBM Inc, Armonk, NY, USA).

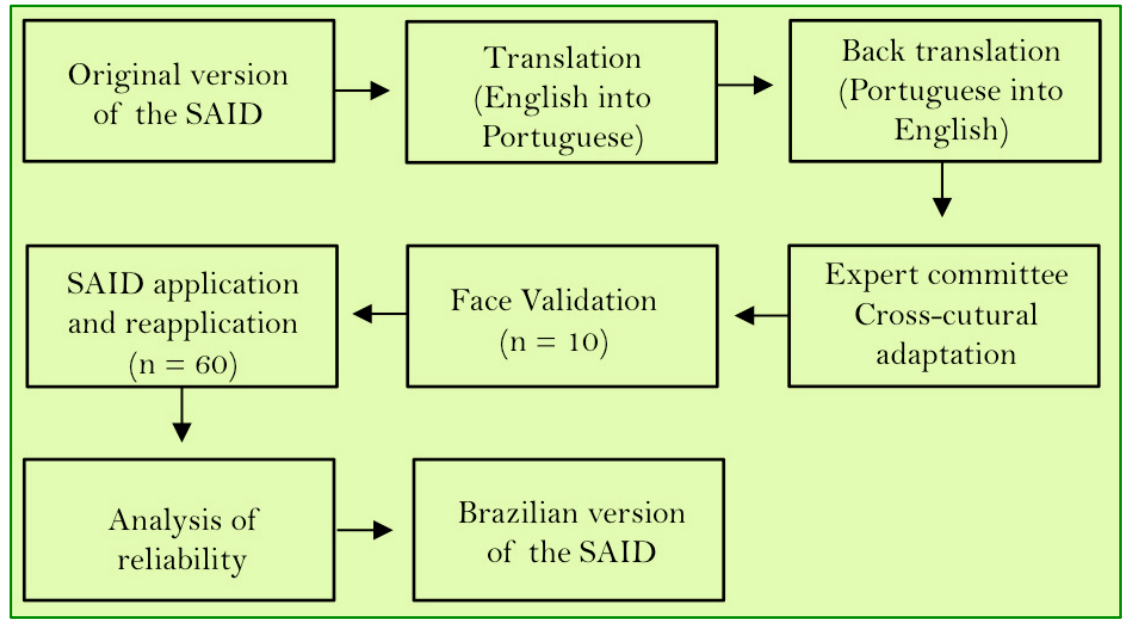

Figure 1. Flowchart of the study.

\section{Results}

Participants' age ranged from 10 to 19 years. Face validation was performed with 10 adolescents, five of each sex, with a mean age of 14.5 years. The translated and adapted instrument was applied in 60 adolescents - 30 of each, with a mean of 13.27 years of age.

The back-translation process confirmed that the translation into Portuguese was reliable. Face validation occurred in a single time, and the mean time to respond to the entire survey was 5'20". The Brazilian version of the SAID was considered easy to understand and not exhaustive, and only a few questions and suggestions were pointed out. Two questions were changed, as follows: "coming to see your dentist” and the word "reduce" were replaced by "your appointment with the dentist" and "decrease", respectively. In addition to the modifications aimed at improving the understanding of the Likert scale, we indicated the space that corresponds to "more or less" and used arrows to indicate the spaces where to write comments or questions to the dentist.

The instrument displayed excellent reliability, with internal consistency (Cronbach's alpha $=0.77)$ and test-retest coefficients (ICC $=0.88 ; 95 \% \mathrm{CI}$ : 0.81-0.93) above the recommended levels. The alpha value per domain is described in Table 1.

Table 1. Cronbach's alpha per domain of the SAID Brazilian version.

\begin{tabular}{lcc}
\multicolumn{1}{c}{ Domain Covered and Items } & Response Format & $\begin{array}{c}\text { Cronbach's } \\
\text { Alpha }\end{array}$ \\
\hline Dental Neglect & Likert Scale & 0.76 \\
Q1. How many times do you brush your teeth daily? & \\
Q11. Do you want to know if there is anything wrong with your teeth? & Face Scale & 0.76 \\
Dental Anxiety & & \\
Q2. How do you feel about your last dental appointment? & \\
Q3. How do you feel about coming to the dentist, in general? & \\
Q4. How do you feel about coming to see your dentist today? &
\end{tabular}


Coping Preferences

Q6. How much would you like to know about your dentist's job?

Q7. Do you like reading pamphlets and fliers?

Q8. Would you like your dentist to explain everything they are doing?

Q10. Would you like to know if you will feel pain?

Q16. How would it feel to see everything your dentist is doing?

Q17. How would it feel to have someone talking to you right now?

Patient's Requests

Q5. How comfortable does your mouth feel today?

Q9. Would you like to know if you will feel discomfort?

Q12. Do you want to know about the dental problems you might have in the future?

Q13. Would you like to ask your dentist about injections?

Q15. Do you have any question for your dentist?

Q20. Do you want to how long it will take to get over the problem you have?

Q21. In your opinion: how much treatment do you need from your dentist today?

Q14. Do you want to know about ways your dentist can reduce discomfort?

Q18. Do you want the dentist to look at a problem you have with your teeth or gums?

Q19. Do you want the dentist to understand a problem you have?

The Kappa results and the degree of agreement of the dichotomous questions indicated that the SAID has good reproducibility (Table 2), except for question \#22. Question \#25 (addressing whether there were any difficult questions to answer) yielded an excellent Kappa coefficient, which confirms that Brazilian adolescents had no difficulty answering the survey. As for descriptive questions, adolescents did not always use the spaces provided to write comments or ask questions to the dentist, but most of them $(58.3 \%)$ wrote something in at least one of the four descriptive questions.

Table 2. Kappa coefficients and the degree of agreement of dichotomous questions.

\begin{tabular}{|c|c|c|c|c|c|}
\hline \multirow[b]{2}{*}{ Item } & \multirow{2}{*}{$\begin{array}{l}\text { Domain } \\
\text { Covered }\end{array}$} & \multicolumn{2}{|c|}{ Degree of Agreement } & \multicolumn{2}{|c|}{ Kappa Coefficient } \\
\hline & & $\begin{array}{l}\text { Intra rater } \\
\text { examiner }\end{array}$ & $\begin{array}{l}\text { Inter rater } \\
\text { examiner }\end{array}$ & Intra-rater & Inter-rater \\
\hline $\begin{array}{l}\text { Q22. Do you want to tell your dentist about } \\
\text { any general discomforts or medical problems } \\
\text { that you have? }\end{array}$ & $\begin{array}{c}\text { Coping } \\
\text { Preferences }\end{array}$ & $58.8 \%$ & $88.1 \%$ & 0.13 & 0.64 \\
\hline $\begin{array}{l}\text { Q23. Have you ever had a bad experience with } \\
\text { a dentist? }\end{array}$ & - & $94.1 \%$ & $87.5 \%$ & 0.82 & 0.59 \\
\hline $\begin{array}{l}\text { Q24. Is there anything you want to } \\
\text { talk to your dentist about? }\end{array}$ & $\begin{array}{l}\text { Patient's } \\
\text { Requests }\end{array}$ & $88.2 \%$ & $75 \%$ & 0.68 & 0.51 \\
\hline $\begin{array}{l}\text { Q25. Are there any questions that were hard to } \\
\text { answer? }\end{array}$ & - & $100 \%$ & $75 \%$ & 1.00 & 0.1 \\
\hline
\end{tabular}

\section{Discussion}

This was the first study in the literature validating the SAID to a foreign language. Since it was a new instrument, the SAID had been only validated by its author [10]. In general, the Brazilian Portuguese version showed satisfactory psychometric properties and proved to be a reliable research instrument.

The cross-cultural adaptation process requires a series of steps to be followed to guarantee that the new version of an instrument captures the same construct by the target population [16]. In our study, the back-translated version of the SAID was very similar to the original one and, therefore, the original meaning was not altered.

The reliability of the instrument was well established in both the internal consistency and test-retest analyses. Cronbach's alpha was considered acceptable $(\geq 0.70)$ [14]. This study was based on the validation of 
the original SAID version and other validation studies, which also determined the Cronbach's alpha coefficient and obtained similar results [10,19-21]. In a New Zealand study, the domain of dental anxiety had an alpha coefficient of 0.89 and the coping scale presented an alpha coefficient of 0.81 [10]. In our study, both parameters showed alpha coefficients of 0.76 and 0.75 , respectively. The ICC results demonstrated excellent stability [18], although the aspects evaluated by the SAID are quite subjective, such as feelings and anxiety. However, we were in charge so that invasive procedures were not performed in both visits. First visit was screening, only. In the original version of the instrument, this property was not evaluated [10].

The Kappa results and the degree of agreement of the dichotomous questions showed good reproducibility of the instrument, except for question \#22 (Do you want to inform your dentist about any general discomforts or medical problems that you have?). However, it is important to note that response agreement variations may occur due to natural fluctuations in the patients' daily lives.

Another aspect to consider was that the SAID was applied to our study participants in printed format. In New Zealand, a pilot study was developed with the printed format of the SAID [11]. Yet, the main clinical trials [10,21] have used a computer-based version of the SAID, which was considered to be more interesting for adolescents because virtual communication is well established in this population [16,22]. Despite this, the printed version was easy to apply and avoided the need for a computer and a printer in the waiting room and their corresponding costs and risks [10].

The motivation for developing the SAID was based on conversations with teenagers. They reported a need for information about oral health and asked dentists to use simple language to describe problems that require treatment - but not to use euphemisms about "insects" (caries) or "magic juice" (anesthetic). The adolescents also reported an inclination for further explanations about the disease process [10,11]. Taken altogether, these aspects highlighted the need for an instrument that particularizes communication between dentists and adolescents, as it is known that better control of anxiety is achieved with a greater level of understanding and good communication [23].

Psychometric validity tests (criterion and construct validity) were not performed, and this is a limitation of this study. Moreover, due to the sample size, the requirements to perform factor analysis were not met. In this sense, difficulty in obtaining an adequate sample size is due to the reason that SAID was designed to be applied specifically in the dental waiting room, as opposed to instruments that can be applied in school environments. Therefore, it is suggested that additional studies evaluate other psychometric properties and test SAID as an intervention for dental anxiety.

\section{Conclusion}

The SAID translation, cross-cultural adaptation and reliability analysis were completed successfully, and the Brazilian version was considered easy to understand by Brazilian adolescents aged 10 to 19 years. This research instrument is suitable for the analysis of dental anxiety, communication, and empathy between the dentist and adolescent patients. Thus, the Brazilian version of the SAID can be a useful survey tool for dental care of adolescent patients.

\section{Authors' Contributions}

\begin{tabular}{|c|c|c|}
\hline GBSM (iD & https://orcid.org/0000-0002-3361-5664 & $\begin{array}{l}\text { Conceptualization, Methodology, Formal Analysis, Investigation, Writing - Original Draft and } \\
\text { Writing - Review and Editing. }\end{array}$ \\
\hline TMAM ID & https://orcid.org/0000-0003-2640-4524 & $\begin{array}{l}\text { Conceptualization, Formal Analysis, Investigation, Writing - Original Draft and Writing - } \\
\text { Review and Editing. }\end{array}$ \\
\hline MGN (iD & https://orcid.org/0000-0003-2402-9505 & Investigation, Writing - Original Draft and Writing - Review and Editing. \\
\hline LJ & https://orcid.org/0000-0003-1419-9244 & Conceptualization, Writing - Review and Editing and Supervision. \\
\hline $\mathrm{VC}$ & https://orcid.org/o000-0003-2912-2100 & $\begin{array}{l}\text { Conceptualization, Methodology, Writing - Original Draft, Writing - Review and Editing and } \\
\text { Supervision. }\end{array}$ \\
\hline
\end{tabular}




\section{Financial Support}

This study was partially supported by the Coordenação de Aperfeiçoamento de Pessoal de Nível Superior - Brasil (CAPES) - Finance Code 001 .

\section{Conflict of Interest}

The authors declare no conflicts of interest.

\section{Data Availability}

The data used to support the findings of this study can be made available upon request to the corresponding author.

\section{References}

[1] Dahl RE. Affect regulation, brain development, and behavioral/emotional health in adolescence. CNS Spectr 2001; 6(1):60-72. https://doi.org/10.1017/s1092852900022884

[2] Schulz KM, Molenda-Figueira HA, Sisk CL. Back to the future: The organizational-activational hypothesis adapted to puberty and adolescence. Horm Behav 2009; 55(5):597-604. https://doi.org/10.1016/j.yhbeh.2009.03.010

[3] Sawyer SM, Azzopardi PS, Wickremarathne D, Patton GC. The age of adolescence. Lancet Child Adolesc Health 2018; 2(3):223-8. https://doi.org/10.1016/S2352-4642(18)30022-1

[4] Albahri AH, Abushibs AS, Abushibs NS. Barriers to effective communication between family physicians and patients in walk-in centre setting in Dubai: a cross-sectional survey. BMC Health Serv Res 2018; $18(1): 637$. https://doi.org/10.1186/s 12913-018-3457-3

[5] Davies EB, Buchanan H. An exploratory study investigating childrens perceptions of dental behavioural management techniques. Int J Paediatr Dent 2013; 23(4):297-309. https://doi.org/10.1111/ipd.12007

[6] Cianetti S, Lombardo G, Lupatelli E, Pagano S, Abraha I, Montedori A, et al. Dental fear/anxiety among children and adolescents. A systematic review. Eur J Paediatr Dent 2017; 18(2):121-30. https://doi.org/10.23804/ejpd.2017.18.02.07

[7] White AM, Giblin L, Boyd LD. The prevalence of dental anxiety in dental practice settings. J Dent Hyg 2017; 91(1):30-4.

[8] Nermo H, Wilumsen T, Johnsen JAK. Prevalence of dental anxiety and associations with oral health, psychological distress, avoidance and anticipated pain in adolescent: a cross sectional study based on the Troms $\varnothing$ study. Acta Odontol Scand 2019; 77(2):126-34. https://doi.org/10.1080/00016357.2018.1513558

[9] Carvalho RWF, Falcão PGCB, Campos GJL, Andrade ESS, Vasconcelos BCE, Pereira MAS. Prevalence and predictive factors of dental anxiety in Brazilian adolescents. J Dent Child 2013; 80(1):41-6.

[10] Jones L. Validation and randomized control trial of the e-SAID, a computerized paediatric dental patient request form, to intervene in dental anxiety. Child Care Health Dev 2015; 41(4):620-5. https://doi.org/10.1111/cch.12200

[11] Jones LM, Huggins TJ. The Rationale and piloty study of a new paediatric dental patient request form to improve communication and outcomes of dental appointments. Child Care Health Dev 2013; 39(6):869-72. https://doi.org/10.1111/j.1365-2214.2012.01416.x

[12] World Health Organization. Young People's Health - a Challenge for Society. Report of a WHO Study Group on Young People and Health for All. Technical Report Series 731. Geneva: WHO, 1986.

[13] World Health Organization. Health for the world's adolescents: a second chance in the second decade. Geneva: WHO, 2014.

[14] Herdman M, Fox-rushby J, Badia X. A model of equivalence in the cultural adaptation of HRQoL instruments: the universalist approach. Qual Life Res 1998; 7(4):323-35. https://doi.org/10.1023/a: 1024985930536

[15] Costa JZ, Meller SN, Behar-Horestein L, Fontanella VRC, Reston EG, Miguens Jr AS. Validation method of research instruments for Dental Radiology curriculum study. Rev ABENO 2018; 18(3):105-13. https://doi.org/10.30979/rev.abeno.v18i3.529

[16] Beaton DE, Bombardier C, Guillemin F, Ferraz MB. Guidelines for the process of cross-cultural adaptation of selfreported measures. Spine 2000; 25(24):3186-91. https://doi.org/10.1097/00007632-200012150-00014

[17] Terwee CB, Bot SD, Boer MC, Van der Windt DA, Knnol DL, Dekker J. Quality criteria were proposed for measurement properties of health status questionnaires. J Clin Epidemiol 2007; 60(1):34-42. https://doi.org/10.1016/j.jclinepi.2006.03.012

[18] Kline P. Handbook of Psychological Testing, 2nd ed. London, UK: Routledge; 2000. 752 p.

[19] Simancas-Pallares M, John MT, Prodduturu S, Rush WA, Enstad CJ, Lenton P. Development, validity and reliability of the Orofacial Esthetic Scale - Spanish version. J Prosthodont Res 2018; 62(4):456-61. https://doi.org/10.1016/j.jpor.2018.05.003

[20] Ferreira AMB, Colares V. Validation of the Brazilian version of the fear of dental pain questionnaire - short form (SFDPQ). Pesqui Bras Odontopediatria Clin Integr 2011; 11(2):275-9. https://doi.org/10.4034/PBOCI.2011.112.20 
[21] Yee R, Jones LM, Hosey MT. What the child "SAID" to the dentist: A UK randomized controlled trial. Child Care Health Dev 2017; 43(6):926-32. https://doi.org/10.1111/cch.12510

[22] Lenhart A. Teen, Social Media and Technology Overview 2015. Pew Research Center. 2015. Available from: https://www.pewresearch.org/internet/2015/04/09/teens-social-media-technology-2015/. [Accessed on November 13, 2019]

[23] Armfield JM, Medon LJ. Management of fear and anxiety in the dental clinic: a review. Aust Dent J 2013; 58(4):390407. https://doi.org/10.1111/adj.12118 